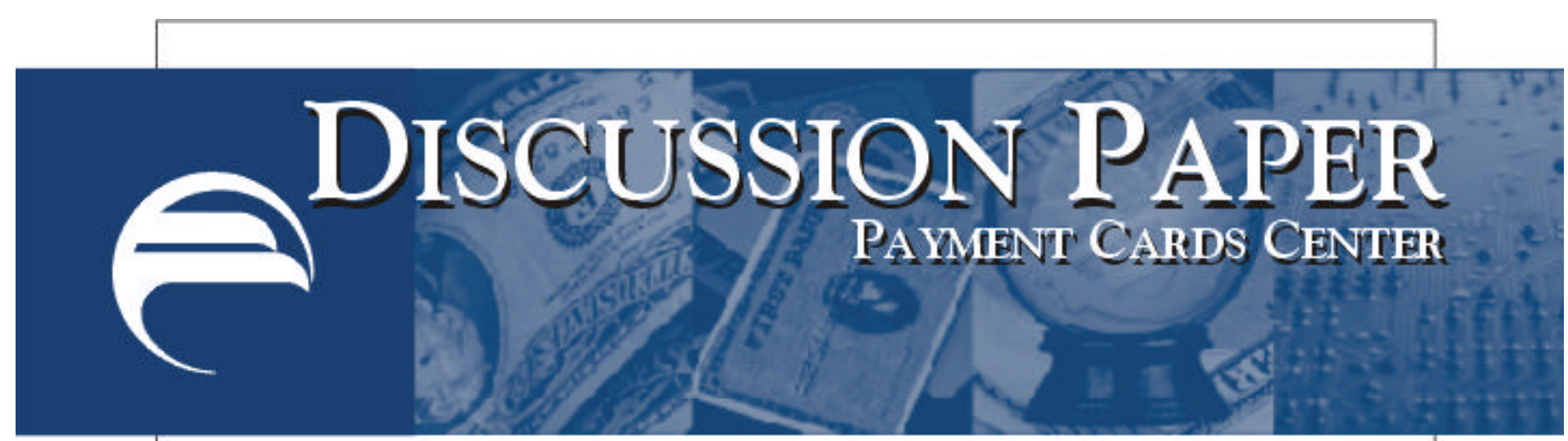

\title{
An Overview and History of Credit Reporting*
}

\author{
Mark Furletti
}

June 2002

Summary: On April 5, 2002, the Payment Cards Center of the Federal Reserve Bank of Philadelphia held a workshop that explored the uses and evolution of credit reporting companies. Leading the workshop was a group of executives from TransUnion LLC - Tony Capaldi, Group Vice President for the Eastern Region; Dan Brackle, Vice President, Philadelphia; and Chet Wiermanski, Vice President, Analytical Services. Headquartered in Chicago, Illinois, TransUnion is a leading global provider of information and decision-processing services, maintaining one of the largest databases of consumer credit information in the world, serving businesses and consumers in the U.S. This paper includes a short history of credit reporting, an overview of the Fair Credit Reporting Act, and a review of credit reporting company markets and uses. Information from the TransUnion workshop is supplemented by additional research.

*The views expressed here are not necessarily those of this Reserve Bank or of the Federal Reserve Svstem.

\section{Federal Reserve Bank of Philadelphia}




\section{Introduction}

Credit reporting companies serve as sources of information about consumers' use of credit as reported by those from whom consumers borrow. Lenders use this information to supplement whatever data they have already directly acquired about a borrower's creditworthiness to make lending decisions. As part of this system, lenders have incentives to report their own experiences with borrowers so as to gain access to other creditors' data in the future.

The credit data essentially represent a consumer's credit "reputation," based as it is on his or her borrowing and repayment behavior over time. In the past, this "reputation" was usually maintained by lots of local agencies working with local lenders with incomplete and often unverifiable information. Today, regulation and consolidation have led to highly automated national firms that compile far more detailed and complete information and comply with a range of policies designed to protect the interest of consumers.

Credit reporting companies give businesses insights into a consumer's past behavior, similar to the ways in which an insurance company might use a driving record or a prospective employer might use a college transcript. These insights, which include a consumer's record of meeting financial obligations, can be used to make decisions about his or her stability and his or her ability and willingness to repay debt. Without such information, borrowers would likely be required to provide far more information about themselves when applying for any type of credit and pay more for access to credit. In fact, in countries that do not have a well-developed credit reporting system, creditors can make the mistake of lending to consumers who are already overextended or in default 
with another creditor. ${ }^{1}$ These mistakes result in a higher cost of borrowing for all consumers.

In his article "What's in the File?" economist Robert M. Hunt explains the importance of credit reporting. ${ }^{2}$ He writes: "Armed with more information, lenders can better evaluate potential borrowers and offer loan terms commensurate with their risk of default. And if future access to credit is a valuable option to a borrower, he or she will have an incentive to avoid a default that might become known to other creditors." So in addition to providing creditors with the information necessary to properly measure risk, credit reporting companies provide incentives for consumers to use credit responsibly. For these reasons, credit reporting companies play an important role in the efficient allocation of consumer credit.

\section{History of Credit Reporting Companies}

Tony Capaldi began the workshop by describing the credit reporting industry during the 1950s and 1960s. For illustrative purposes, he focused on the history of agencies in the tri-state area (Pennsylvania, Delaware, and New Jersey) and indicated that similar events were unfolding nationally. The first "bureaus," as they were called then, in the tri-state area were small and community based. "They often tracked the behaviors of consumers in a specific county or town and primarily focused on serving one kind of creditor— bank, finance company, or retailer," Capaldi said.

These early credit reporting companies represented cooperative efforts among creditors in a specific region and were operated solely for the benefit of its members. They typically limited their credit-related reporting to negative or "derogatory"

\footnotetext{
${ }^{1}$ Kate Gibson, "Lending Abroad: The Credit Concept Spreads," Collections \& Credit Risk (August 2001).
} 
information (e.g., delinquencies or defaults). For example, a group of retailers in a small town might have agreed to form a cooperative that kept track of customers who were considered delinquent by any member of the group. The individual merchants would then use this information in managing their own credit relationships with prospective and current customers.

In addition to capturing name, address, and some loan information, these early agencies would scour local newspapers for notices of arrests, promotions, marriages, and deaths. These notices would then be clipped and attached to a consumer's paper credit report.

Requests or "inquiries" from creditors to see a particular consumer's information would also be noted in the report. These inquiries would indicate that a consumer was requesting credit. In those early days and throughout the 1960s, the credit reporting business was industry specific in its focus. As such, bank-, retailer-, or finance companysponsored "bureaus" did not share loan or inquiry information with each other. This kept banks from knowing about loans or inquiries made by finance companies or retailers and vice versa. The situation limited any creditor's ability to understand a potential customer's entire debt situation.

The political, technological, and market pressures that exerted themselves on the credit reporting industry during the 1970 s played an important role in shaping the modern-day credit reporting company. The decade began with passage of the Fair Credit Reporting Act (FCRA). Described in more detail below, the FCRA protected consumers by setting standards for accuracy of and access to their credit information. Subsequent to

\footnotetext{
${ }^{2}$ Robert M. Hunt, "What's in the File? The Economics and Law of Information Sharing in Consumer Credit Markets," Federal Reserve Bank of Philadelphia Business Review, Second Quarter 2002, p.18.
} 
the FCRA's passage, the industry stopped reporting things like marriages, promotions, and arrests and focused its efforts on reporting verifiable credit-related information. This included both positive information, such as a consumer's ability to consistently pay her bills on time, as well as negative information, such as defaults and delinquencies.

Also during this decade, the industry harnessed the power of computers and databases to process, organize, and report on credit data. Those agencies that adopted computer technology realized operating efficiencies that allowed them to move data faster and attract more business. This, along with the costs associated with migrating to computer-based systems, compelled smaller operations that were not yet automated to sell their files and exit the industry.

As a result of this consolidation and in order to meet the demands of an exploding unsecured lending market, credit reporting companies started including lending activity from banks, finance companies, and retailers from wider geographic areas. ${ }^{3}$ By the end of the 1970s, a handful of companies, also called consumer reporting agencies (CRAs), emerged as leaders. Capaldi explained that in the tri-state area, TransUnion and TRW (now Experian) became the dominant players by acquiring or aligning themselves with many of the smaller agencies. Similar events played out in other regions across the U.S., contributing to the market penetrations that the three major bureaus still have today.

By the start of the 1980s, the content, storage, and processing of credit reports had changed dramatically. More accurate information (e.g., names, addresses, and Social Security numbers) was electronically stored and accompanied by loan, inquiry, and public record information (e.g., bankruptcies, judgments, and liens). Histories that were

\footnotetext{
${ }^{3}$ According to the Federal Reserve, consumers' revolving unsecured debt grew from $\$ 4$ billion to $\$ 54$ billion during the 1970s
} 
once read over the phone to an inquiring business were now transmitted electronically. Overall, computer technology, market forces, and the FCRA had provided credit reporting companies with the impetus to transform themselves from "local associations" or "bureaus" that clipped wedding announcements from newspapers to "efficient integrated systems serving an entire society."4

\section{The Fair Credit Reporting Act}

First passed by Congress in 1970 and subsequently amended in 1996, the Fair Credit Reporting Act (FCRA) set forth the rules by which credit reporting companies must operate and interact with creditors and consumers. ${ }^{5}$ According to the Federal Trade Commission (FTC), the FCRA was "designed to protect the privacy of consumer report information and to guarantee that the information supplied by consumer reporting agencies is as accurate as possible." To accomplish this, the FCRA established the following consumer rights:

- Consumers must be told if information in their file is used against them.

- Consumers must be able to find out what is in their file.

- Consumers have the right to dispute inaccurate information and have inaccurate information corrected or deleted.

- Outdated information (e.g., bankruptcies more than 10 years old) cannot be reported.

- Consumer consent is required for reports provided to employers.

- Consumers can request that their names be excluded from lists for unsolicited credit and insurance offers.

\footnotetext{
${ }^{4}$ Daniel B. Kline, "Credit Information Reporting," The Independent Review, p. 331.

${ }^{5}$ Daniel B. Kline, "Credit Information Reporting," The Independent Review, p. 327.
} 
- Consumers who are identified by name on a list of prospects requested by a creditor must be extended an offer of credit.

In addition to ensuring that consumer information is accurate and properly maintained, the FCRA specifically details the parties that can have access to credit data. Recognizing the inherent dangers of the indiscriminant distribution of personal financial information, the FCRA restricts access to credit reporting company data to only those with a "permissible purpose." The following is a list of some of the most relevant permissible purposes:

- In connection with a credit transaction;

- For employment purposes;

- In connection with the underwriting of insurance;

- In connection with determining eligibility for a license or other government benefit;

- In response to a court order;

- In connection with valuing or assessing the credit or prepayment risks associated with an existing credit obligation; and

- In response to a request by the head of a child-support enforcement agency.

The FCRA was amended in 1996 to further protect consumers. These amendments make credit reporting companies liable for knowingly reporting misinformation and allow consumers to take legal action against individuals who obtain a report without a permissible purpose. In addition, the amendments require that credit reporting companies investigate errors within a set period of time, allow for the prescreening and postscreening of consumers by potential creditors, and allow banks to 
share credit information with affiliates as long as consumers are given the opportunity to prohibit this sharing. ${ }^{6}$

\section{Providing and Gaining Access to Credit Data}

Following a discussion of the FCRA, Chet Wiermanski described the processes by which businesses gain access to credit data. For creditors seeking to use credit information for marketing purposes, credit reporting companies enforce a "give-to-get" policy. Essentially, a lender cannot get credit file information about a potential customer with whom he wishes to do business unless the lender provides information to the company about customers with whom he does business. This policy ensures that lenders who benefit from a credit reporting company's competitive intelligence are themselves exposed to the same data-reporting efforts of their peers.

In addition to enforcing "give-to-get," credit reporting companies must arbitrate "permissible purpose" as defined by the FCRA. Wiermanski described how, upon request from a business to begin obtaining consumer credit data, the credit reporting company will perform various investigations and checks to ensure the legitimacy of the business's purpose. This process can include reference checks and an on-site inspection. Once the business has established itself as having a permissible purpose, it can begin reporting and requesting data from credit reporting companies. Depending on the size of the business, data about customers can be transferred to the credit reporting company as frequently as each day and can be sent over phone lines or via electronic media (e.g., CD or tape). Upon receipt of the data, credit reporting companies conduct a series of tests to ensure that the data are valid.

\footnotetext{
${ }^{6}$ Robert H. Cole and Lon Mishler, Consumer and Business Credit Management, $11^{\text {th }}$ ed. (McGraw-Hill, 1998), pp. 205-06.
} 
Once the data pass these tests, they are posted to consumers' files. If the credit reporting company does not have a record for a customer because he or she is establishing credit for the first time, it will create a new credit report for that person with his or her name, address, and loan information. The credit reporting company will also perform checks on the entire database to ensure that there are no duplicate or mixed (i.e., having information from more than one person) files.

\section{Competition Among Credit Reporting Companies}

The majority of the data on a consumer's credit report, including loan information, liens, bankruptcies, and judgments, are reported by creditors and courts to all three major credit reporting companies - TransUnion, Equifax, and Experian. So if someone were to examine the file information of one customer at all three credit reporting companies, information about this customer would generally be the same.

One element that distinguishes one credit reporting company from another, Wiermanski explained, is its inquiry data. These inquiries are of two basic kinds: hard and soft. A hard inquiry is typically driven by a consumer's request for credit from a place such as a bank, credit card company, or finance company. Hard inquiries are incorporated into most credit-scoring schemes because consumers shopping for additional credit are riskier than those who are not. A soft inquiry is one made by a creditor who may already have a relationship with the consumer. These inquiries are used for account management purposes and are not shared on the credit report with other creditors. Soft inquiries are not factored into credit-scoring schemes.

"To a large extent, inquiries are regionally driven," said Wiermanski. That is, creditors are more likely to make inquiries of a credit reporting company because it has a 
historically dominant presence in the area where a prospective borrower lives. For example, if a credit card issuer wants a credit report on a customer who lives in Pennsylvania, it is likely to use TransUnion as a primary source and one of the other two major companies as a secondary source. Similarly, the same issuer might use Experian as a primary source of credit information in another area and Equifax in another. This is driven by the fact that these companies have formed relationships with or acquired many of a region's small reporting agencies. Through these relationships or acquisitions, they have become the credit reporting company of choice for lenders in those regions. Overall, lenders want to use the credit reporting company that is most likely to have captured the majority of inquiries for a given customer for risk-assessment purposes. Given this situation, businesses often maintain zip code preference tables that guide their decisions about which credit reporting companies to use for specific geographic areas.

Wiermanski also pointed out that, as consumers have become more credit savvy in terms of shopping for the best rates and terms, risk models have had to modify their usage of inquiry data. In the past, each individual inquiry was considered an attempt by the consumer to shop for additional credit. With consumers now often consulting many lenders for a single loan, these models have been changed to consider multiple inquiries made within 15 or 30 days of each other as just one for risk-assessment purposes.

Wiermanski noted that in addition to capturing inquiries, "credit reporting companies also differentiate themselves by the degree to which they can process inquiries and loan data quickly." Given the risk implications of making a lending decision with information that is weeks or months old, issuers have pressed credit reporting companies to maintain files that are as up-to-date as possible. 
An article that appeared in the American Banker explained other ways by which credit reporting companies differentiate themselves. ${ }^{7}$ By selling products such as customized scoring models and advice on how to optimally use those products, credit reporting companies are transforming themselves from information vendors to business partners. Wiermanski, who was quoted in the article, said, "Customers are coming to us [TransUnion] more frequently for recommendations. Instead of just presenting empirical data we're saying what are the optimal pricing strategies for a given portfolio." By dispensing such advice, credit reporting companies hope to add value to the data they provide and deepen their customer relationships.

\section{Credit Reporting Companies and Credit Card Issuers}

Given the Payment Cards Center's focus on issues affecting the credit card industry, we should note the ways in which card issuers leverage credit data. The most obvious of these ways is in evaluating an application for a new credit card. Issuers incorporate data from credit reporting companies into the underwriting process, either manually through a credit analyst's review or automatically through computer creditscoring models. In both cases, data from credit reporting companies are central to decisions about whether to extend credit, how much credit should be extended, and the price of the credit (i.e., annual percentage rate).

Credit card issuers, however, use credit data in other, less traditional ways, both before and after making the decision to lend. Issuers may use credit data both as part of a screening mechanism for their new-account marketing efforts and as a decision-making tool for customer management efforts.

\footnotetext{
${ }^{7}$ W. A. Lee, “Credit-Reporter-as-Adviser Adds TransUnion,” American Banker, May 13, 2002.
} 
A few examples of these less traditional uses are:

\section{- Acquisition}

Credit card issuers have a long history of using data from credit reporting companies to formulate acquisition campaigns. Issuers give credit reporting companies screening criteria and, in turn, receive a list of potential customers that meet those criteria. For example, an issuer may want to get a list of consumers who are low risk as determined by their credit score, who maintain balances of at least $\$ 20,000$ with other credit card issuers, and who have never been late on their mortgage or seriously delinquent on any other loan. The credit reporting company will then give the issuer the names and addresses of consumers who meet these requirements. Upon receipt of these names, the issuer is required by the Fair Credit Reporting Act to make the consumers who meet these criteria a firm offer of credit.

\section{- Retention}

Each day credit card issuers receive calls from disgruntled customers who demand that their interest rate be lowered. Given these requests and the intense competition in the industry for growth, issuers have become increasingly sophisticated in their ability to negotiate individual rates with customers. Using aggregated data from credit reporting companies (e.g., the sum total of unsecured revolving balances), issuers can choose to offer low rate promotions to customers who are willing to transfer large revolving balances away from competitors. If a credit reporting company shows that a customer doesn't have any revolving balances, but he or she has several open 
accounts, the issuer may try to retain that customer with a rewards program instead of a lower rate. If neither is the case and the relationship has been unprofitable, the issuer may be willing to let the customer close his or her account without any significant retention offer. In this way, the credit bureau helps issuers gather competitive intelligence, gauge a customer's potential profitability, and tailor appropriate retention offers.

\section{- Penalty Pricing}

Over the past few years, issuers have inserted language in their credit card solicitations that states: "Your APRs may increase if you fail to make a payment to us or any other creditor when due." By reviewing information from credit reporting companies monthly or quarterly and checking a customer's payment history with other creditors, issuers can be alerted to deterioration in credit quality. Armed with this information, issuers will raise an increasingly risky customer's interest rate. An effective penalty-pricing strategy, therefore, relies heavily on the constant monitoring of data from credit reporting companies.

\section{New Markets: Beyond Lending}

An article in the Wall Street Journal in March 2001 began: "Maybe you were forced to put down a big deposit when you got phone service. You might have ended up paying extra-high rates for auto insurance despite a flawless driving record. Or, maybe you suddenly had trouble finding homeowner's insurance." 8

\footnotetext{
${ }^{8}$ Ruth Simon, "Numbers Game: Looking to Improve Your 'Credit Score'?” Wall Street Journal, March 2001.
} 
In the article, the writer went on to explain that all of these could be the result of a bad credit score — the basis of which is the data in a consumer's credit file. Once used exclusively by credit grantors to make lending decisions, credit data now help a wide range of organizations make financial and nonfinancial decisions about consumers.

During the workshop, Dan Brackle described how "any company that performs a service or delivers goods prior to receiving a payment is effectively doing so on the basis of credit and may have an interest in a consumer's credit file." He said that these potential creditors include electric, gas, oil, water, cable, long distance, and cellular phone providers. Other organizations with a legitimate business purpose include insurance companies, potential employers, hospitals, and brokerage firms. These organizations can often use information from credit reporting companies to do the following:

- Determine product/service eligibility;

- Extend offers of employment;

- Target new products and promotions;

- Find those with delinquent accounts;

- Verify consumers' names and addresses; and

- Formulate strategies for collections.

As evidence of the expanding market for credit data, Brackle pointed to TransUnion's own experience in the Philadelphia area. Banks and credit unions, which were once the primary users of data from credit reporting companies, have been overtaken by a range of nonbank entities, including hospitals, telecommunication companies, utilities, and brokerage firms. Brackle mentioned that demand from utilities and telecommunications is fueled by the need to examine the creditworthiness of 
customers who will receive services (e.g., power or mobile phone service) before actually paying for them.

\section{Credit Reporting Companies and Macroeconomic Forecasting}

At the workshop's conclusion, Wiermanski also spoke about TransUnion's efforts to model and forecast macroeconomic variables using credit data. Leveraging a data set that contains time series data for 30 million anonymous consumers, TransUnion can provide its customers with trends and forecasts for select risk metrics (e.g., delinquency rates or bankruptcy rates) at the company, product, and regional levels. These forecasts, which incorporate macroeconomic data, can assist lenders in the development of their marketing and underwriting criteria.

TransUnion's efforts highlight the fact that credit reporting companies possess data that can be used for far more than loan approval, insurance pricing, and employment decisions. When aggregated, these data can effectively measure and foreshadow the economic health of the U.S. consumer.

\section{Conclusion}

Once an obscure and widely misunderstood document, the consumer credit file has become one of the most important decision-making tools used by traditional retail lenders. Its use in serving other "permissible purposes" for an expanding range of businesses is growing rapidly. As consumers come to understand the reach and influence of credit reports, they will have an interest in verifying and monitoring the data being reported by the credit reporting companies. Anticipating increased demand for credit by consumers, credit reporting companies are already working to enhance their raw credit reporting data with consumer-oriented information that makes reading the reports easier. 
Arguably, the passage of the Fair Credit Reporting Act and the introduction of computer technology were two events that left an indelible mark on the industry. Overall, the reliability and quality of information, and indeed the integrity of borrowers' "reputations," have been greatly enhanced since the early days of incomplete and often anecdotal information manually reported by unregulated local bureaus. 